\title{
A photoswitchable rotaxane operating in monolayers on solid support $\uparrow$
}

Cite this: Chem. Commun., 2016, 52, 14458

Received 25th October 2016, Accepted 24th November 2016

DOI: $10.1039 / \mathrm{c} 6 \mathrm{cc} 08586 \mathrm{e}$

www.rsc.org/chemcomm

\author{
Felix B. Schwarz, ${ }^{a}$ Thomas Heinrich, ${ }^{\text {ab }}$ Andreas Lippitz, ${ }^{\text {b }}$ Wolfgang E. S. Unger*b \\ and Christoph A. Schalley*a
}

\begin{abstract}
A novel photoswitchable rotaxane was synthesised and its switching behaviour in solution was analysed with NMR and UV-Vis. A monolayer of rotaxanes was deposited on glass surfaces and the on-surface photoswitching was investigated. Angle-resolved NEXAFS spectra revealed a preferential orientation that reversibly changes upon switching.
\end{abstract}

Photochromic molecules are widely used as key components in stimuli-responsive molecular switches and machines. Common photoswitches like azobenzenes, spiropyranes and dithienylethenes offering a fast and clean photoisomerisation have been utilised in the development of complex functional systems and materials. ${ }^{1-7}$ Especially, mechanically interlocked molecules (MIMs) like rotaxanes have been investigated intensely in this context. ${ }^{1,5-7}$ The transfer of MIMs from solution into ordered arrays at interfaces is of great interest, as such order is the prerequisite for macroscopic effects through the concerted action of microscopic units. ${ }^{8-11}$ Several examples for the deposition of MIMs on surfaces are reported in the literature. ${ }^{12-14}$ However, there are only a few examples for surface-bound photoresponsive MIM-based systems. ${ }^{15-17}$

Recently, we reported the photoinduced pseudorotaxane formation of a photoresponsive axle and a tetralactam macrocycle carried out in solution and on surfaces with immobilized multilayers of macrocycles. ${ }^{18}$ Here, we report a photoswitchable rotaxane, consisting of a tetralactam macrocycle (TLM) and a photoswitchable axle. The axle is comprised of an azobenzene photoswitch and a diketopiperazine binding site, which are both attached to a rigid xanthene backbone in a way that the azobenzene photoisomerisation influences the binding strength of the adjacent site by steric hindrance. By substitution with a suitable linker, this photoswitchable axle was used as the central

\footnotetext{
${ }^{a}$ Institut für Chemie und Biochemie, Freie Universität Berlin, Takustr. 3, 14195 Berlin, Germany. E-mail: c.schalley@fu-berlin.de

${ }^{b}$ BAM - Federal Institute for Materials Research and Testing, Unter den Eichen 44-46, 12203 Berlin, Germany. E-mail: wolfgang.unger@bam.de

$\dagger$ Electronic supplementary information (ESI) available: Experimental procedures, surface preparation, additional NMR, MS, XPS and NEXAFS data. See DOI: $10.1039 / \mathrm{c} 6 \mathrm{cc} 08586 \mathrm{e}$
}

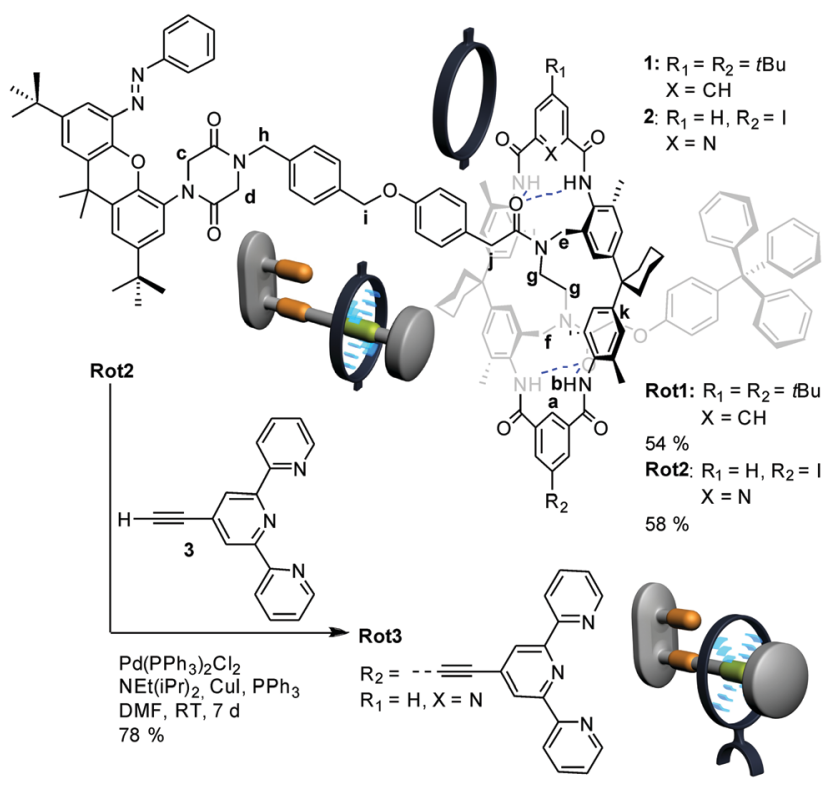

Fig. 1 Synthesis of photoswitchable rotaxanes Rot1, Rot2 and Rot3.

building block for rotaxanes, serving as the photoswitch, the first binding site and the stopper simultaneously. The second part of the axle contains a diamide binding site, ${ }^{19}$ which bears a bulky trityl stopper on one end and a linker unit at the other end. Rotaxanes Rot1 and Rot2 were obtained in a one-step etherrotaxane synthesis from two axle building blocks and TLM 1 or 2 (Fig. 1). Rot3 functionalised with a terpyridine unit at the TLM was synthesised in one step starting from Rot2 in a Sonogashira coupling reaction with acetylene-functionalised terpyridine 3 (ESI $\dagger$ ). Rot1 containing the di-tert-butyl substituted TLM 1 was used for all solution studies due to its good solubility, while Rot3 was used for surface experiments.

The formation of Rot1 was followed by ${ }^{1} \mathrm{H}$ NMR spectroscopy, confirming the threaded structure with the TLM being located at the diamide and not at the diketopiperazine binding site (Fig. 2d(i and ii) and ESI $\dagger$ ). The mechanically interlocked 


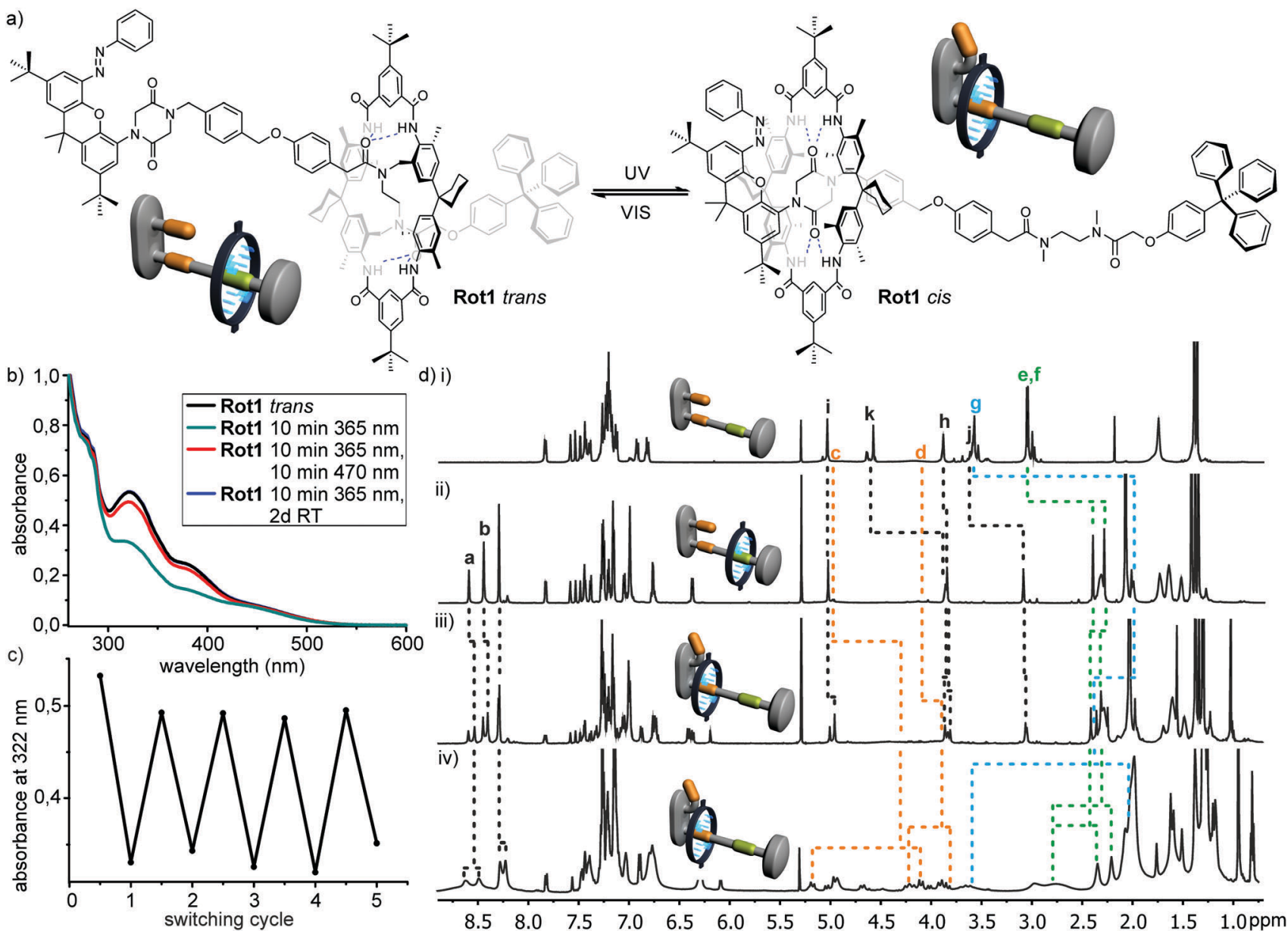

Fig. 2 (a) Photoswitching of Rot1. (b) UV-Vis spectra of trans-Rot1 in $\mathrm{CH}_{2} \mathrm{Cl}_{2}$ (black), Rot1 after 10 min irradiation at $\lambda_{1}=365 \mathrm{~nm}$ (green), Rot1 after irradiation at $\lambda_{1}=365 \mathrm{~nm}$ and $\lambda_{2}=470 \mathrm{~nm}$ for $10 \mathrm{~min}$ each (red), and Rot1 after 10 min irradiation with $365 \mathrm{~nm}$ and subsequent equilibration for $2 \mathrm{~d}$ at $30{ }^{\circ} \mathrm{C}$ in the dark (blue, overlapping with black spectrum). (c) Reversibility of photoswitching of Rot1 in $\mathrm{CH}_{2} \mathrm{Cl}_{2}$ tested by alternating irradiation at $\lambda_{1}=365 \mathrm{~nm}$ and $\lambda_{2}=470 \mathrm{~nm}$ for $10 \mathrm{~min}$ in each step. (d) ${ }^{1} \mathrm{H}$ NMR spectra of the free axle in $\mathrm{CDCl}_{3}$ at RT (i), trans-Rot1 in CDCl 3 at RT (ii), cis : trans $2: 1$ at RT (iii) and cis : trans $2: 1$ at $228 \mathrm{~K}$ (iv).

structure of Rot1 was confirmed by IRMPD ESI-FTICR-MS experiments (ESI $\dagger$ ).

The photoswitching of Rot1 was studied in solution by UV-Vis and NMR spectroscopy. Photoisomerisation of the azobenzene group in Rot1 from trans to cis was carried out by irradiation with an LED lamp at a wavelength of $\lambda_{1}=365 \mathrm{~nm}$. Back-switching was carried out by irradiation at $\lambda_{2}=470 \mathrm{~nm}$ or thermal equilibration. The UV-Vis spectrum of trans-Rot1 in $\mathrm{CH}_{2} \mathrm{Cl}_{2}$ displays a broad absorption band at $c a .520 \mathrm{~nm}$ and a characteristic absorption band for the $\pi \rightarrow \pi^{*}$ transition of azobenzene at $322 \mathrm{~nm}$ (Fig. 2b). ${ }^{20}$ Irradiation at $\lambda_{1}=365 \mathrm{~nm}$ leads to a decrease in intensity of the $\pi \rightarrow \pi^{*}$ absorption band, indicating the formation of cis-Rot1. Irradiating the sample at $\lambda_{2}=470 \mathrm{~nm}$ induces back-switching to trans-Rot1 up to ca. $90 \%$. In both cases, the photostationary state was reached after 10 minutes. Complete back-isomerisation to trans-Rot1 was accomplished by equilibrating the sample in the dark at $35{ }^{\circ} \mathrm{C}$ over two days. Reversibility was investigated by alternating irradiation at $\lambda_{1}=365 \mathrm{~nm}$ and $\lambda_{2}=470 \mathrm{~nm}$ over five cycles (Fig. 2c). ${ }^{1} \mathrm{H}$ NMR spectra of Rot1 were measured before and after irradiation at $\lambda_{1}=365 \mathrm{~nm}$ for $10 \mathrm{~min}$ (Fig. $2 \mathrm{~d}($ ii and iii)). In the spectrum after irradiation, a second set of signals for cis-Rot1 is observed with a ratio of $c i s-$ :trans-Rot1 of $c a$. $2: 1$. The protons $\mathrm{a}$ and $\mathrm{b}$ of the macrocycle undergo a small shift upfield in cisRot1 compared to trans-Rot1, indicating a different binding situation. The protons $\mathrm{c}$ and $\mathrm{d}$ of the diketopiperazine site are shifted upfield by 0.73 and $0.15 \mathrm{ppm}$, while the protons $\mathrm{e}, \mathrm{f}$ and $\mathrm{g}$ of the diamide site are shifted downfield by $0.05,0.06$ and $0.42 \mathrm{ppm}$. This leads to the conclusion that the macrocycle is moving from the diamide towards the diketopiperazine binding site. In comparison with the ${ }^{1} \mathrm{H}$ NMR spectrum of the free axle and the shifts observed in a previous binding study with the corresponding pseudorotaxane, ${ }^{18}$ the shifts of the binding site protons $\mathrm{c}-\mathrm{g}$ upon switching of Rot1 are smaller than expected. Likely, the macrocycle undergoes a shuttling motion between the two binding sites which is fast on the NMR time scale (see below).

The binding constants for both binding sites in Rot1 were determined by NMR titrations using structurally analogous model compounds containing one binding site each. For the diketopiperazine site, binding constants of $1650 \pm 170 \mathrm{M}^{-1}$ 
when the azobenzene is in its cis configuration and $<15 \mathbf{M}^{-1}$ when the azobenzene is in the trans configuration were obtained. ${ }^{18}$ For the diamide site, a binding constant of $1400 \pm 140 \mathrm{M}^{-1}$ was determined (ESI $\dagger$ ). Although the diketopiperazine represents the favoured binding site, the small difference in binding energy will rather lead to a molecular shuttle than to a rotaxane switch with two distinct positions of the macrocycle.

Temperature-dependent NMR spectra in a range between $300 \mathrm{~K}$ and $228 \mathrm{~K}$ have been recorded to investigate the shuttling of cis-Rot1 (ESI $\dagger$ ). Upon cooling the sample, the peak for the macrocycle protons a at $8.52 \mathrm{ppm}$ in the ${ }^{1} \mathrm{H}$ NMR spectra gets broadened, undergoes coalescence at approximately $243 \mathrm{~K}$ and splits into two signals at 8.63 and $8.50 \mathrm{ppm}$ upon further cooling, indicating a shuttling motion which is slow on the ${ }^{1} \mathrm{H}$ NMR timescale. At $228 \mathrm{~K}$, the signals for protons $\mathrm{c}$ and $\mathrm{d}$ of the diketopiperazine site split into two sets at 5.20 and $4.12 \mathrm{ppm}$ for c respectively 4.24 and $3.87 \mathrm{ppm}$ for $\mathrm{d}$. The signals for the protons $\mathrm{e}, \mathrm{f}$, and $\mathrm{g}$ for the diamide site split as well into signals at 2.93 and $2.86 \mathrm{ppm}$ for e, 2.25 and $2.86 \mathrm{ppm}$ for $\mathrm{f}$ and 2.11 and $3.59 \mathrm{ppm}$ for $\mathrm{g}$ (Fig. 2d(iv)). This implies that three different species are present: trans-Rot1 with the macrocycle being located at the diamide site, cis-Rot1 with the macrocycle being located at the diketopiperazine site and cis-Rot1 with the macrocycle at the diamide site. Integration of the signals in the NMR spectrum at $228 \mathrm{~K}$ yields an overall ratio of Rot1 with the macrocycle at the diketopiperazine site to Rot1 with the macrocycle at the diamide site of approximately $2: 3$. Due to the very complex spectra and broad signals, a more detailed analysis of the shuttling behavior was not straightforward.

After the rotaxane switching was investigated in solution, the concept was transferred to surfaces by following previously established procedures for surface deposition. ${ }^{21}$ A monolayer of rotaxanes was deposited on surfaces using metal-ion/pyridine/ terpyridine coordination chemistry. ${ }^{22-27}$ Cleaned glass slides have been used as the substrates for UV surface experiments and contact angle measurements, while silicon substrates were used for XPS and NEXAFS experiments. A self-assembled monolayer of PDS was deposited on the surface by immersing the substrate in a $5 \mathrm{mM}$ solution of PDS. The surfaces were then treated with a $1 \mathrm{mM}$ solution of tetrakis(acetonitrile)palladium(II) tetrafluoroborate to coordinate the pyridyl endgroups of PDS with palladium(II) ions, followed by immersion in a $1 \mathrm{mM}$ solution of Rot3 to create a monolayer of rotaxanes on the surface (Fig. 3a). The deposition of Rot3 was followed by UV-Vis spectroscopy (Fig. 3b). As the glass slides absorb light below $300 \mathrm{~nm}$, only the region above this value could be used. A substantial increase in absorbance was detected after deposition of Rot3, which resembles the UV-Vis spectra of Rot1 in solution and therefore indicates a successful monolayer formation. XPS measurements show a molecular ratio of Rot3 to PDS of $1: 15$.

To investigate on-surface switching, a surface functionalised with a monolayer of Rot3 was irradiated with an LED lamp at a wavelength of $\lambda_{1}=365 \mathrm{~nm}$ or $\lambda_{2}=470 \mathrm{~nm}$ from a distance of about $20 \mathrm{~cm}$. Different irradiation times were investigated and it was found that in case of $\lambda_{1}=365 \mathrm{~nm}$, no further changes in the absorbance spectra occurred after an irradiation time a)
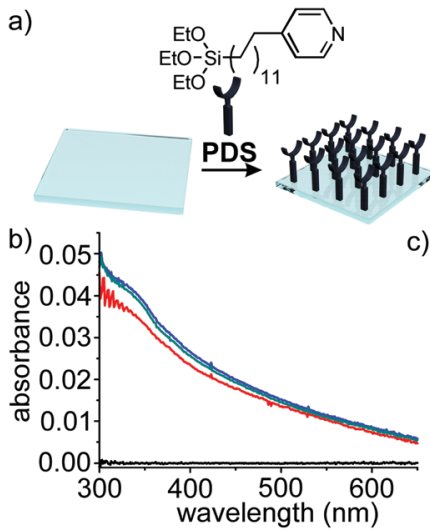

c) $\underline{\xi}$
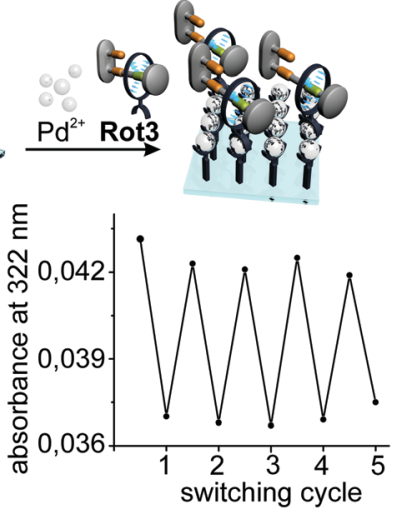

Fig. 3 (a) Surface deposition of Rot3, (b) transmission UV-Vis spectra of surfaces, PDS (black), PDS-Pd-Rot3 (blue), PDS-Pd-Rot3 1 h 365 nm (red) and PDS-Pd-Rot3 $1 \mathrm{~h} 365 \mathrm{~nm}, 1.5 \mathrm{~h} 470 \mathrm{~nm}$ (green; superimposing the blue curve), (c) reversibility of the on-surface photoswitching tested over five cycles.

of $1 \mathrm{~h}$, while it took $1.5 \mathrm{~h}$ in case of $\lambda_{2}=470 \mathrm{~nm}$. After irradiation at $\lambda_{1}=365 \mathrm{~nm}$, the UV-Vis spectra of the surface showed a decrease in absorbance in the region between 300 and $500 \mathrm{~nm}$, indicating the formation of cis-Rot3. After irradiation at $\lambda_{2}=470 \mathrm{~nm}$, the absorbance of the surface increased up to about $90 \%$ of its initial value, indicating almost complete back-switching to trans-Rot3. Reversibility was tested over five switching cycles (Fig. 3c). In a second approach, surfaces were functionalised with a covalently bound monolayer of rotaxanes by azide-alkyne click chemistry, which resulted in a similar photoswitchability, but a less dense packing (ESI $\dagger$ ).

Contact angle measurements were conducted for a monolayer of Rot3 that reveal a strong and reversible change in polarity upon photoswitching of the surfaces (ESI $\dagger$ ). To prove successful rotaxane deposition and the structural effects of the rotaxane switching as well, angle-resolved C K-edge NEXAFS spectroscopy was conducted for the pristine rotaxane monolayer of Rot3 on silicon, the monolayer after $1 \mathrm{~h}$ irradiation with $\lambda_{1}=365 \mathrm{~nm}$, and after $1 \mathrm{~h}$ light irradiation with $\lambda_{1}=365 \mathrm{~nm}$ with subsequent $1.5 \mathrm{~h}$ irradiation at $\lambda_{2}=470 \mathrm{~nm}$ as seen in Fig. 4 . In the $55^{\circ} \mathrm{C}-\mathrm{K}$ edge spectrum of the pristine rotaxane layer, the characteristic $\pi^{*}$ resonance splitting for pyridines and benzene is visible. ${ }^{27}$ Furthermore, the peak at $285.4 \mathrm{eV}$ is significantly more intense than the peak at $284.9 \mathrm{eV}$. Together with the intense $\pi^{*}$ resonance in the $\mathrm{N}-\mathrm{K}$ edge spectrum (Fig. S28, ESI $\dagger$ ) at $399.4 \mathrm{eV}$, which is characteristic for Pd-coordinated pyridine, ${ }^{28}$ with a shoulder at $398.6 \mathrm{eV}\left(\pi^{*} \mathrm{O}=\mathrm{C}-\mathrm{N}\right)$ characteristic for the axle molecule, ${ }^{18}$ and with XPS data (Fig. S30 and $\mathrm{S} 31, \mathrm{ESI} \dagger$ ) this clearly indicates the successful deposition of the rotaxane. The pristine monolayer of trans-Rot3 shows a relatively small, but clearly visible linear dichroism for the $\mathrm{C}$ K-edge $\pi^{*}$ and $\sigma^{*}$ resonances. ${ }^{29}$ Irradiation with light at $\lambda_{1}=365 \mathrm{~nm}$ results in a decrease of the linear dichroism in the $\mathrm{C}$ K-edge which is regained upon subsequent irradiation with $\lambda_{2}=470 \mathrm{~nm}$. In context of the solution study and the fact that the position of the macrocycle is fixed in trans-Rot3, but variable in cis-Rot3, a higher order in the monolayer when the rotaxane is switched to its trans-state can be assumed. The relatively small magnitude of 


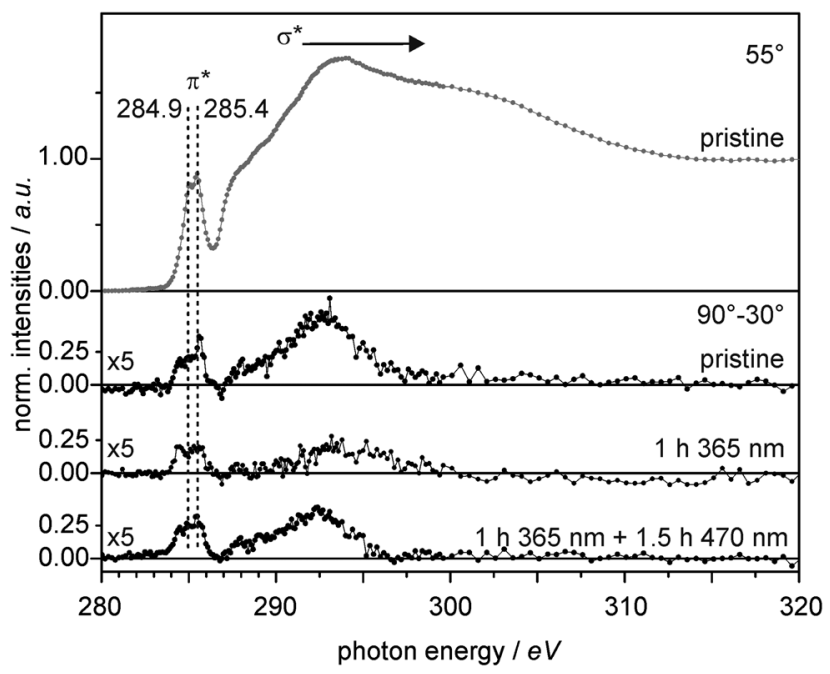

Fig. $455^{\circ} \mathrm{C}$ K-edge NEXAFS spectrum of the pristine rotaxane monolayer and its $90^{\circ}-30^{\circ}$ difference spectrum. Difference spectra after $1 \mathrm{~h}$ irradiation with $\lambda=365 \mathrm{~nm}$, and after $1 \mathrm{~h}$ irradiation with $\lambda=365 \mathrm{~nm}$ followed by $1.5 \mathrm{~h}$ irradiation with $\lambda=470 \mathrm{~nm}$ (peak assignments are given in $\mathrm{eV}$ ).

the linear dichroism effect might be due to a rather sparse packing in the monolayer resulting in lower preferential orientation of the immobilized molecules. Due to the exclusively photo-induced modification of the rotaxane states, the observed differences in linear dichroism can be associated with the switching states of Rot3. However, the analysis does not provide a quantification of the on-surface switching process.

In the present study, we developed a photoswitchable rotaxane and analysed its switching behavior in solution as well as in a monolayer of rotaxanes deposited on glass and silicon surfaces. NEXAFS spectroscopy revealed a preferential orientation in the monolayer, which reversibly changes upon photo switching of the rotaxane. In combination with chemically switchable rotaxanes, we are aiming for multi-stimuli responsive surface systems capable of performing concerted switching of distinct layers resulting in potential macroscopic effects.

We are grateful to the Deutsche Forschungsgemeinschaft (SFB 765) for funding. F. B. S. thanks the Beilstein Institut for a PhD fellowship. The authors thank Dr A. Nefedov (Karlsruhe Institute of Technology, KIT) from the HE-SGM Collaborate Research Group at the synchrotron facility BESSY II and Dr A. Vollmer and M. Mast (all HZB/BESSY II) for support during our activities at HZB. We thank Prof. Biprajit Sarkar for providing the catalyst for surface reactions.

\section{Notes and references}

1 N. Katsonis, M. Lubomska, M. M. Pollard, B. L. Feringa and P. Rudolf, Prog. Surf. Sci., 2007, 82, 407-434.

2 W. R. Browne and B. L. Feringa, Annu. Rev. Phys. Chem., 2009, 60, 407-428.

3 M.-M. Russew and S. Hecht, Adv. Mater., 2010, 22, 3348-3360.

4 R. Klajn, Pure Appl. Chem., 2010, 82, 2247.

5 M. Baroncini, G. Ragazzon, S. Silvi, M. Venturi and A. Credi, Pure Appl. Chem., 2015, 87, 537.

6 R. H. El Halabieh, O. Mermut and C. J. Barrett, Pure Appl. Chem., 2004, 76, 1445.

7 S. Erbas-Cakmak, D. A. Leigh, C. T. McTernan and A. L. Nussbaumer, Chem. Rev., 2015, 115, 10081-10206.

8 A. Coskun, M. Banaszak, R. D. Astumian, J. F. Stoddart and B. A. Grzybowski, Chem. Soc. Rev., 2012, 41, 19-30.

9 M. M. Boyle, R. A. Smaldone, A. C. Whalley, M. W. Ambrogio, Y. Y. Botros and J. F. Stoddart, Chem. Sci., 2011, 2, 204-210.

10 J. J. Davis, G. A. Orlowski, H. Rahman and P. D. Beer, Chem. Commun., 2010, 46, 54-63.

11 A. C. Fahrenbach, S. C. Warren, J. T. Incorvati, A.-J. Avestro, J. C. Barnes, J. F. Stoddart and B. A. Grzybowski, Adv. Mater., 2013, 25, 331-348.

12 V. Balzani, A. Credi and M. Venturi, ChemPhysChem, 2008, 9, 202-220.

13 E. Coronado, P. Gavina and S. Tatay, Chem. Soc. Rev., 2009, 38, 1674-1689.

14 Y. Liu, A. H. Flood, P. A. Bonvallet, S. A. Vignon, B. H. Northrop, H.-R. Tseng, J. O. Jeppesen, T. J. Huang, B. Brough, M. Baller, S. Magonov, S. D. Solares, W. A. Goddard, C.-M. Ho and J. F. Stoddart, J. Am. Chem. Soc., 2005, 127, 9745-9759.

15 I. Willner, V. Pardo-Yissar, E. Katz and K. T. Ranjit, J. Electroanal. Chem., 2001, 497, 172-177.

16 P. Wan, Y. Jiang, Y. Wang, Z. Wang and X. Zhang, Chem. Commun., 2008, 5710-5712.

17 J. Berna, D. A. Leigh, M. Lubomska, S. M. Mendoza, E. M. Perez, P. Rudolf, G. Teobaldi and F. Zerbetto, Nat. Mater., 2005, 4, 704-710.

18 F. B. Schwarz, T. Heinrich, J. O. Kaufmann, A. Lippitz, R. Puttreddy, K. Rissanen, W. E. S. Unger and C. A. Schalley, Chem. - Eur. J., 2016, 22, 14383-14389.

19 L. Kaufmann, E. V. Dzyuba, F. Malberg, N. L. Low, M. Groschke, B. Brusilowskij, J. Huuskonen, K. Rissanen, B. Kirchner and C. A. Schalley, Org. Biomol. Chem., 2012, 10, 5954-5964.

20 J. Griffiths, Chem. Soc. Rev., 1972, 1, 481-493.

21 C. H. H. Traulsen, V. Kunz, T. Heinrich, S. Richter, M. Holzweber, A. Schulz, L. K. S. von Krbek, U. T. J. Scheuschner, J. Poppenberg, W. E. S. Unger and C. A. Schalley, Langmuir, 2013, 29, 14284-14292.

22 J. J. Richardson, M. Björnmalm and F. Caruso, Science, 2015, 348, 6233.

23 V. Piñón and M. Weck, Langmuir, 2012, 28, 3279-3284.

24 Y. Chaikin, H. Leader, R. Popovitz-Biro, A. Vaskevich and I. Rubinstein, Langmuir, 2011, 27, 1298-1307.

25 P. C. Mondal, J. Yekkoni Lakshmanan, H. Hamoudi, M. Zharnikov and T. Gupta, J. Phys. Chem. C, 2011, 115, 16398-16404.

26 G. de Ruiter, M. Lahav and M. E. van der Boom, Acc. Chem. Res., 2014, 47, 3407-3416.

27 N. Tuccitto, I. Delfanti, V. Torrisi, F. Scandola, C. Chiorboli, V. Stepanenko, F. Wurthner and A. Licciardello, Phys. Chem. Chem. Phys., 2009, 11, 4033-4038.

28 S. Richter, J. Poppenberg, C. H. H. Traulsen, E. Darlatt, A. Sokolowski, D. Sattler, W. E. S. Unger and C. A. Schalley, J. Am. Chem. Soc., 2012, 134, 16289-16297.

29 T. Heinrich, C. H. H. Traulsen, M. Holzweber, S. Richter, V. Kunz, S. K. Kastner, S. O. Krabbenborg, J. Huskens, W. E. S. Unger and C. A. Schalley, J. Am. Chem. Soc., 2015, 137, 4382-4390. 